\title{
Radiological Diagnosis and Differential Diagnosis of Headache
}

\section{Radiologische Diagnostik und Differenzialdiagnostik bei Kopfschmerzen im Erwachsenenalter}

Authors

Affiliation
S. Langner, M. Kirsch

Institute for Diagnostic Radiology and Neuroradiology, Universitymedicine Greifswald, Germany

Key words
brain
head/neck
CT
MR-imaging

received $\quad 9.7 .2014$

accepted 27.1.2015

Bibliography

Dol http://dx.doi.org/

10.1055/s-0034-1399140

Published online: 2.9.2015

Fortschr Röntgenstr 2015; 187 :

879-891 @ Georg Thieme

Verlag KG Stuttgart · New York .

ISSN 1438-9029

\section{Correspondence}

PD Dr. Sönke Langner

Institut für Diagnostische

Radiologie und Neuroradiologie, Universitätsmedizin Greifswald Ferdinand-Sauerbruch-Str. 1

17475 Greifswald

Germany

Tel.: ++49/3834/866960

Fax: ++49/3834/867097

langso@uni-greifswald.de

\section{Abstract \\ $\nabla$}

Headache is very common and affects almost everyone at some point. It is one of the most common disorders that leads patients to see their physician. All different forms have the nociception via trigeminal nerve fibers in common. Beside the clinical course headaches are classified as either primary or secondary, with the latter having an identifiable structural or biochemical cause. Imaging has a low diagnostic yield in primary headache but play an important role in the differential diagnosis of secondary forms. An overview of different forms of secondary headache is given, outlining diagnostic procedures and the morphologic imaging features of each syndrome.

Key points:

- Headache can be differentiated in primary and secondary forms.

- Imaging plays an important role in differential diagnosis of secondary forms.

- Imaging should be performed in patients with concomitant systemic or neurologic symptoms.

Citation Format:

- Langner S, Kirsch M, Hosten N Radiological Diagnosis and Differentialdiagnosis of Headache. Fortschr Röntgenstr 2015; 187: 879-891

\section{Zusammenfassung \\ $\nabla$}

Kopfschmerzen sind eine der häufigsten Beschwerden, die zu einem Arztbesuch führen, und betreffen nahezu jeden einmal in seinem Leben. Gemeinsame pathophysiologische Endstrecke ist die Schmerzwahrnehmung über Trigeminusäste. Neben der Verlaufsform kann hinsichtlich der Ursache zwischen primären und sekundären Kopfschmerzen unterschieden werden, wobei die sekundären Kopfschmerzen Ausdruck einer zugrunde liegenden Erkrankung sind. Ist die diagnostische Ausbeute bei primären Kopfschmerzen gering, so spielt die Bildgebung bei den sekundären Formen eine entscheidende Rolle in der Differenzialdiagnostik. Verschiedene sekundäre Kopfschmerzformen werden vorgestellt und die zur Verfügung stehenden diagnostischen Verfahren sowie die bildmorphologischen Korrelate der einzelnen Krankheitsbilder beschrieben.

\section{Introduction \\ $\nabla$}

Almost everyone gets headaches at least once in life; they are among the most common complaints resulting in a visit to a physician. In the literature, their prevalence is indicated to be between $31-96 \%$ among adults [1]. This wide variance is due to varying definitions, age as well as gender-related and ethnic differences. Thus headaches are reported more frequently in North America and Europe compared to Asia and South America [1]. Kolmann et al. showed that women exhibited a 40 - 70\% 7-day/12-month prevalence of headaches, compared to men who exhibited a $20-$ $50 \%$ prevalence [2].

Brain tumors, with an incidence of 46 per 100000 are rarely the cause; however, in adults, headaches are the initial symptom in $65 \%$ of affected adults. Even lower is the incidence of subarachnoid hemorrhage (SAH) at 6-7 cases per 100000 , but headaches are the cardinal symptom in more than $75 \%$ of affected patients [3]. In many patients, when a headache first occurs, there is the fear of a severe underlying illness, and there is high expectation that this will be ruled out using imaging.

The current classification of the International Headache Society [4] distinguishes between 
Table 1 Classification of headache according to the International Headache Society (IHS) (modified according to [7]).

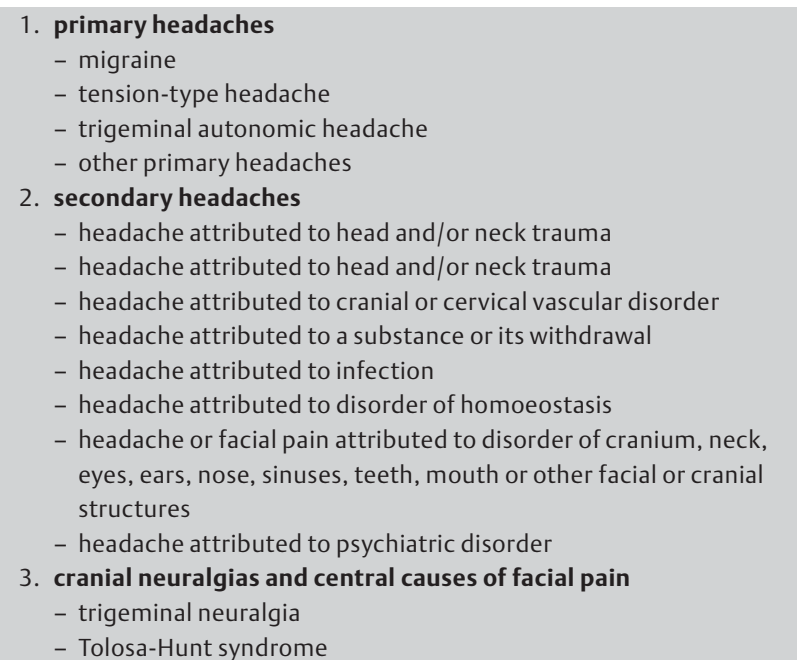

primary and secondary headache as well as cranial neuropathies and facial pain ( $\bullet$ Table 1 ). The pathophysiology of headaches is not fully understood in all cases; however, the common final pathway of all symptom clusters is the perception of pain via trigeminal branches.

This review article will discuss primary and frequent secondary headache in adults as well as examination protocols and strategies for individual symptom patterns.

\section{Examination Protocols and Strategies \\ $\nabla$}

The necessity of imaging and selection of examination modality are primarily dependent on the expected symptom cluster. Additional factors may also include local availability of different examination modalities, the age of the patient and general clinical situation, such as accompanying unconsciousness.

In every case, imaging is indicated in the presence of red flags, including appearance of headaches in cancer or HIVpositive patients, if headaches first appear in a patient after 50 years of age as well as headaches with increasing intensity, accompanying systemic reaction such as fever or focalneurological deficit $[5,6]$.

In emergency situations when patients have potentially life-threatening causes, e.g. in cases of subarachnoid hemorrhage or headache with accompanying unconsciousness, CT is the preferred diagnostic method due to the shorter examination time as well as better access to the patient and easier monitoring of the patient during the examination.

A CT-based examination protocol ( $\bullet$ Table 2 ) should include a non-enhanced $\mathrm{CT}$ with an orbital-meatal angulation from the base of the skull to the vertex. This can use a sequential technique as well as a spiral CT with newer equipment. Image data should be reconstructed in the soft tissue and bone window.

If there is suspicion of a vascular process, an arterial or venous CT angiography can follow. An arterial angiography is performed after intravenous administration of $60 \mathrm{ml}$ of an
Table 2 Basic examination protocol for CT and MRI in cases of headache.

\begin{tabular}{|l|l|}
\hline CT & indication/attribute \\
\hline technique & exclude hemorrhage, mass, infarction \\
\hline Non-enhanced CT & - incremental CCT with orbital-meatal layer orientation \\
- 4.5 mm slice thickness, supra- and infratentorial \\
- reconstruction in soft tissue and bone window
\end{tabular}

$\mathrm{T} 1 \mathrm{w}=\mathrm{T} 1$-weighted images; $\mathrm{DWI}=$ diffusion-weighted imaging; $\mathrm{T} 2 \mathrm{w}=\mathrm{T} 2$-weighted images; $\mathrm{T} 2{ }^{*} \mathrm{~W}=\mathrm{T} 2$-weighted gradient echo images; $\mathrm{CTA}=$ arterial $\mathrm{CT}$ angiography; $C T V$ - venous $C T$ venography; $M R A=M R$ angiography; $M R V=M R$ venography; $\mathrm{CE}=$ contrast enhanced

iodine-based contrast agent with a concentration of $300 \mathrm{mg}$ iodine/ $\mathrm{ml}$ with a flow rate of $6 \mathrm{ml} / \mathrm{sec}$ (64/128-slice MDCT) or $4 \mathrm{ml} / \mathrm{sec}$ (8/16-slice MDCT). The scan direction is caudocranial; the examination uses semiautomatic bolus tracking started at cervical vertebrae 5/6 if a threshold of $150 \mathrm{HE}$ has been exceeded. In order to simplify planning of potential endovascular therapy, the scan region should extend from the aortic arch to the vertex. Venous CT angiography is performed in craniocaudal scan direction after intravenous administration of $80 \mathrm{ml}$ contrast media using a scan delay of $45 \mathrm{sec}$ with a $3 \mathrm{ml} / \mathrm{sec}$ flow rate. Using a shorter scan delay increases the risk of insufficient contrast of the brain nerves.

If in the non-enhanced CT there is suspicion of an infectious or inflammatory event, a contrast-enhanced examination should be performed 5 minutes after administration of the contrast agent. It should be noted, however, that MRI is superior to CT as verification of inflammatory changes.

MR-based diagnosis ( $\bullet$ Table 2 ) should be performed using a head coil. Care should be taken that examinations be performed in at least two mutually orthogonal planes using two different weightings.

Using default $3 \mathrm{~T}$, the authors acquire a T1-weighted (T1w) 3-D data record with a $1 \mathrm{~mm}$ isotropic resolution and sec- 
Table 3 Special examination protocols for CT and MRI.

\begin{tabular}{|c|c|c|c|c|c|c|c|c|c|c|}
\hline migraine & SAH & RCVS & $\begin{array}{l}\text { pituitary } \\
\text { apoplexy }\end{array}$ & dissection & $\begin{array}{l}\text { sinus| } \\
\text { venous } \\
\text { thrombosis }\end{array}$ & $\begin{array}{l}\text { intracranial } \\
\text { cysts }\end{array}$ & infections & $\begin{array}{l}\text { cerebral pseu- } \\
\text { dotumors }\end{array}$ & $\begin{array}{l}\text { CSF leak } \\
\text { syndrome }\end{array}$ & $\begin{array}{l}\text { trigeminal } \\
\text { neuralgia }\end{array}$ \\
\hline MRI & CT & CT & MRI & MRI & MRI & MRI & MRI & MRI & MRI & MRI \\
\hline $\begin{array}{l}\text { primary } \\
\text { modality }\end{array}$ & $\begin{array}{l}\text { primary } \\
\text { modality }\end{array}$ & $\begin{array}{l}\text { often pri- } \\
\text { mary } \\
\text { modality } \\
\text { for SAH }\end{array}$ & $\begin{array}{l}\text { primary } \\
\text { modality }\end{array}$ & $\begin{array}{l}\text { primary } \\
\text { modality }\end{array}$ & $\begin{array}{l}\text { primary } \\
\text { modality }\end{array}$ & $\begin{array}{l}\text { standard } \\
\text { program }\end{array}$ & $\begin{array}{l}\text { primary } \\
\text { modality } \\
\text { for ence- } \\
\text { phalitis }\end{array}$ & $\begin{array}{l}\text { primary } \\
\text { modality }\end{array}$ & $\begin{array}{l}\text { primary } \\
\text { modality }\end{array}$ & primary modality \\
\hline $\begin{array}{l}\text { standard } \\
\text { protocol }\end{array}$ & $\begin{array}{l}\text { non-en- } \\
\text { hanced CT }\end{array}$ & $\begin{array}{l}\text { non-en- } \\
\text { hanced CT }\end{array}$ & $\begin{array}{l}\text { standard } \\
\text { protocol }\end{array}$ & $\begin{array}{l}\text { standard } \\
\text { protocol }\end{array}$ & $\begin{array}{l}\text { standard } \\
\text { program }\end{array}$ & $\begin{array}{l}\text { sag. CISS to } \\
\text { assess posi- } \\
\text { tional rela- } \\
\text { tionship of } \\
\text { aqueduct, } \\
\text { midbrain }\end{array}$ & $\begin{array}{l}\text { standard } \\
\text { program }\end{array}$ & $\begin{array}{l}\text { ax T2w to as- } \\
\text { sess ventricle, } \\
\text { orbits, optic } \\
\text { nerve pathway } \\
\text { and bulbar } \\
\text { configuration }\end{array}$ & $\begin{array}{l}\text { head: ax } \\
\text { T2w to } \\
\text { assess } \\
\text { possible } \\
\text { hygroma }\end{array}$ & $\begin{array}{l}\text { ax T2w to exclude } \\
\text { demyelinating/in- } \\
\text { flammatory foci }\end{array}$ \\
\hline \multirow[t]{2}{*}{$\begin{array}{l}\text { for struc- } \\
\text { tural le- } \\
\text { sion T1w } \\
\text { ( } 5 \text { min) } \\
\text { post-con- } \\
\text { trast on at } \\
\text { least } 2 \\
\text { planes }\end{array}$} & arterial CTA & $\begin{array}{l}\text { arterial } \\
\text { CTA }\end{array}$ & $\begin{array}{l}\text { cor T2w to } \\
\text { distin- } \\
\text { guish op- } \\
\text { tic chias- } \\
\text { ma }\end{array}$ & $\begin{array}{l}\text { ax T1w to } \\
\text { assess wall } \\
\text { hematoma }\end{array}$ & CE-MRV & & $\begin{array}{l}\text { T1w post- } \\
\text { contrast } \\
\text { on at least } \\
2 \text { planes }\end{array}$ & $\begin{array}{l}\text { cor T2w to } \\
\text { assess optic } \\
\text { nerve sheath }\end{array}$ & $\begin{array}{l}\text { spine: } \\
\text { sag T2w fs } \\
\text { to assess } \\
\text { epidural } \\
\text { fluid } \\
\text { cor T2w to } \\
\text { assess } \\
\text { menin- } \\
\text { geal di- } \\
\text { verticula }\end{array}$ & $\begin{array}{l}\text { TOF MRA } \\
\text { ax CISS to detect } \\
\text { neurovascular } \\
\text { compression }\end{array}$ \\
\hline & & & $\begin{array}{l}\text { T1w post- } \\
\text { contrast } \\
\text { cor and } \\
\text { sag }\end{array}$ & $\begin{array}{l}\text { CE MRA of } \\
\text { craniocervi- } \\
\text { cal arteries }\end{array}$ & $C T$ & $C T$ & & $\begin{array}{l}\text { CE MRV to as- } \\
\text { sess transverse } \\
\text { sinus }\end{array}$ & & \\
\hline$C T$ & $M R I$ & MRI & & & CCT & $\begin{array}{l}\text { primarily for } \\
\text { colloid cysts }\end{array}$ & $C T$ & & & $\begin{array}{l}\text { Tolosa-Hunt } \\
\text { syndrome }\end{array}$ \\
\hline \multirow[t]{6}{*}{$\begin{array}{l}\text { only if } \mathrm{Cl} \\
\text { for MRI, or } \\
\text { MRI not } \\
\text { available }\end{array}$} & if neg. CCT & $\begin{array}{l}\text { primary } \\
\text { modality } \\
\text { for follow- } \\
\text { up }\end{array}$ & $C T$ & $C T$ & CTV & & $\begin{array}{l}\text { primary } \\
\text { modality } \\
\text { to exclude } \\
\mathrm{Cl} \text { prior to } \\
\text { LP }\end{array}$ & & & $M R I$ \\
\hline & $\begin{array}{l}\text { + TOF angio- } \\
\text { graphy }\end{array}$ & $\begin{array}{l}\text { standard } \\
\text { protocol }\end{array}$ & $\begin{array}{l}\text { only if } \mathrm{Cl} \\
\text { for MRI, or } \\
\text { MRI not } \\
\text { available }\end{array}$ & $\begin{array}{l}\text { CCT } \\
\text { CTA }\end{array}$ & & & & & & primary modality \\
\hline & & $\begin{array}{l}\text { + TOF an- } \\
\text { giography }\end{array}$ & & & & & & & & standard program \\
\hline & $D S A$ & & & & & & & & & cor and ax T1w \\
\hline & $\begin{array}{l}\text { If CTA am- } \\
\text { biguous } \\
\text { for endo- }\end{array}$ & & & & & & & & & $\begin{array}{l}\text { post-contrast to } \\
\text { detect inflamma- } \\
\text { tory lesions }\end{array}$ \\
\hline & $\begin{array}{l}\text { vascular } \\
\text { therapy }\end{array}$ & & & & & & & & & \\
\hline
\end{tabular}

$\mathrm{Cl}=$ contraindications; $\mathrm{LP}=$ lumbar puncture; $\mathrm{ax}=$ axial layer orientation; $\mathrm{cor}=$ conronal layer orientation; $\mathrm{fs}=$ fat-saturated imaging .

ondary reconstruction on the axial and coronal plane. Using 1.5 T MR systems, axial T1w images are acquired with a $4 \mathrm{~mm}$ slice thickness.. These are each followed by an axial T2-weighted (T2w) FLAIR sequence with a $3 \mathrm{~mm}$ slice thickness. In this sequence particular attention is paid to the complete signal suppression of the CSF. If this is lacking, it can be an indication of subarachnoid hemorrhage or an inflammatory event. However, it should be noted that CSF signal suppression might be due to additional pathological causes such as acute stroke, leptomeningeal metastasis, administration of supplemental oxygen, or physiological processes such as CSF pulsation [7]. In addition, images taken of all the patients include sagittal T2w images with $3 \mathrm{~mm}$ slice thickness to assess the midbrain and brain stem, axial $\mathrm{T} 2{ }^{*} \mathrm{w}$ sequences to detect microhemorrhages as well as axial diffusion-weighted images with $5 \mathrm{~mm}$ slice thickness and two diffusion factors $\left(b=0 / 1000 \mathrm{~s} / \mathrm{mm}^{2}\right)$.

If there is a related clinical suspicion of a vascular process, arterial angiography employing the TOF (time-of-flight) technique can be used or performed as a contrast-enhanced MR angiography (CE MRA). Routinely, representation of the intracranial vessels uses TOF due to the higher spatial resolution than CE MRA for extracranial vessels [8]. As a rule, time-resolved CE MRA offers a diagnostic advantage only when there is suspicion of intracranial arteriovenous malformation, and therefore has not been established in clinical practice. 
Likewise, various techniques are available for MR venography. Due to the brief required examination time and low susceptibility to artifacts, contrast-enhanced MR angiography is regularly performed in clinical practice. The procedure involves injection of $0.1 \mathrm{mmol} \mathrm{Gd}$ per $\mathrm{kg}$ of bodyweight.

Depending upon the medical issue, the examination protocol can be modified just as in CT imaging ( $\bullet$ Table 3 ).

Intra-arterial angiography using DSA does not play a role in the primary diagnosis of headache.

\section{Primary Headache}

$\nabla$

Primary headache is the cause of $84 \%$ of reported cases. Pain itself is the disorder and can have a number of causes. Such headaches include tension headache, cluster headache and migraine. Imaging only rarely yields indicatory findings [3-5]. Due to the possibility of incidental findings that are not necessarily causal for headache, but which may have therapeutic consequence, the case for imaging should be strongly made [5].

Structural abnormalities in cases of primary headache are generally found among patients with a migraine and can best be identified using MRI $[9,10]$. This particularly concerns women and patients with migraine and accompanying aura. It could thus be shown that patients with migraine exhibit an increased incidence of lesions of the white matter [11]. These concern changes which appear hyperintense in T2w or FLAIR images, and which in T1w images do not exhibit enhancement after contrast agent is administered. Although over the course of time these lesions can increase, the clinical relevance of this change is not understood $[11,12]$.

In addition, by using functional MR imaging such as restingstate fMRI or VBM (voxel-based morphometry) analysis, it could be shown that, compared to healthy subjects, patients with primary headache can exhibit changes in the connectivity of the brain and regional differences in the distribution of gray matter [13]. Nevertheless, these results require further research and have yet to be integrated into routine clinical practice.

For migraine patients, imaging is primarily indicated when there are changes in the type, duration and frequency of previously identified headaches or if there is a prolonged aura. In this case an MRI should be performed ( $\bullet$ Table 3 ). If a non-enhanced examination does not reveal abnormalities, then administration of contrast agent can be omitted. As a rule, imaging of the intracranial vessels is not indicated.

\section{Thunderclap Headache}

The thunderclap headache (TCH) is a sudden headache reaching maximum intensity within a few minutes. The term was originally used to characterize headache among patients with SAH (see Secondary Headache) which occurs in only $11 \%$ of patients with $\mathrm{TCH}$, however [14]. There are also a number of additional causes of TCH ( $\bullet$ Table 4 ) and primary $\mathrm{TCH}$ is a diagnosis by exclusion [4].

\section{Secondary Headache}

$\nabla$

In a minority of cases, secondary headache is symptomatic of a different underlying disorder. Following are descriptions of frequent symptom patterns and related changes disclosed by imaging.

\section{Subarachnoid Hemorrhage Etiology}

In $75-85 \%$ of cases [15], non-traumatic SAH is related to a rupture of an aneurysm of vessels supplying the brain. Socalled perimesencephalic nonaneurysmal subarachnoid hemorrhage accounts for $15 \%$ of cases [15]; the cause of this is abnormal venous drainage into the subarachnoid space. In approx. $5 \%$ of cases, SAH has a different cause, such as dissection of the intracranial vertebral artery [16].

\section{Symptomology}

Thunderclap headache is the cardinal symptom in more than $75 \%$ of patients Here, patients with perimesencephalic SAH frequently exhibit a less fulminant onset of headache. In addition, clinical symptoms can range from minor complaints to coma. Patients with perimesencephalic SAH generally experience a more favorable clinical outcome.

\section{Imaging}

When there is clinical suspicion, the imaging method of choice ( $\diamond$ Table 3 ) is CCT with CTA $[15,16]$. In non-enhanced CCT, the subarachnoid space appears hyper-dense in cases of SAH, whereas aneurysmal SAH is typically localized in the basal and ambient cisterns ( $\bullet$ Fig. 1 ). In comparison, perimesencephalic SAH is localized in the interpeduncular and prepontine cisterns ( $\bullet$ Fig. 1 ) Since blood distribution is not pathognomic, a CTA must be performed in cases of perimesencephalic SAH, however. The literature describes CT sensitivity for the detection of SAH as $100 \%$ within the first 6 hours after the event; after 24 hours, sensitivity decreases to $93 \%$, and after 4 days, it declines to $50 \%$ [17].

FLAIR imaging during MRI is suitable for the detection of $\mathrm{SAH}$. Subarachnoid blood causes the intrathecal space to appear hyperintense in FLAIR [18].

In the primary diagnosis of SAH, CTA has replaced angiography using DSA, which as a rule is only still employed in cases of ambiguous CTA findings or as part of endovascular therapy $[15,16]$.

If there is clinical suspicion of SAH, and in the absence of evidence of intracranial blood in the CT or MRI, the suspected diagnosis must be excluded or confirmed via lumbar puncture, since in such cases, spinal SAH must be considered [19].

\section{Reversible Cerebral Vasoconstriction Syndrome Etiology}

Reversible cerebral vasoconstriction syndrome (RCVS) should be considered as part of a differential diagnosis of patients with $\mathrm{TCH}$ and unremarkable CSF as well as indication of segmented diameter variations of the intracranial vessels in the CT or MR angiography ( $\bullet$ Fig. 1). This is a heterogeneous group of disorders associated with reversible segmental vasospasm of the intracranial vessels [20]. The primary differential diagnosis is the isolated angiitis of the CNS, where patients with RCVS typically exhibit reversibil- 
ity of the vascular changes within 4 weeks after symptom onset $[14,21]$.

\section{Symptomology}

Just as in cases of SAH, thunderclap headache is the leading symptom in $95 \%$ of patients; patients with RVCS frequently complain of recurring headaches.

\section{Imaging}

Due to the clinical symptom profile, patients with RVCS are frequently examined using CCT or CTA. Unlike SAH, the basal cisterns are usually hypodense. Using CTA, narrow vessels with significant diameter variations can be demonstrated ( $\bullet$ Fig. 1). With such symptoms, a differential diagnosis should also consider the possibility of SAH with consecutive vasospasms no longer detectable in the CT, so that lumbar puncture should be recommended [19].

Follow-up should entail MR imaging ( $\bullet$ Table 3 ), since in such cases diffusion-weighted images can reliably detect infarcts as a possible complication [22]. Due to method-related higher sensitivity required to detect diameter variations, imaging of the intracranial arteries should employ TOF angiography compared to contrast-enhanced angiography (CE MRA) [23]. However, it should be considered that the resolution of MRA is less than that of CTA.

Table 4 Thunderclap headache differential diagnosis (modified according to [12]).

\begin{tabular}{l} 
primary TCH \\
secondary TCH \\
\hline subarachnoid hemorrhage \\
reversible vasoconstriction syndrome \\
\hline pituitary apoplexy \\
\hline dissection of craniocervical arteries \\
sinus or venous thrombosis \\
\hline colloid cysts of third ventricle \\
\hline spontaneous CSF suppression syndrome \\
\hline hypertensive crisis \\
\hline stroke \\
\hline primary headache related to coughing/gender \\
\hline
\end{tabular}
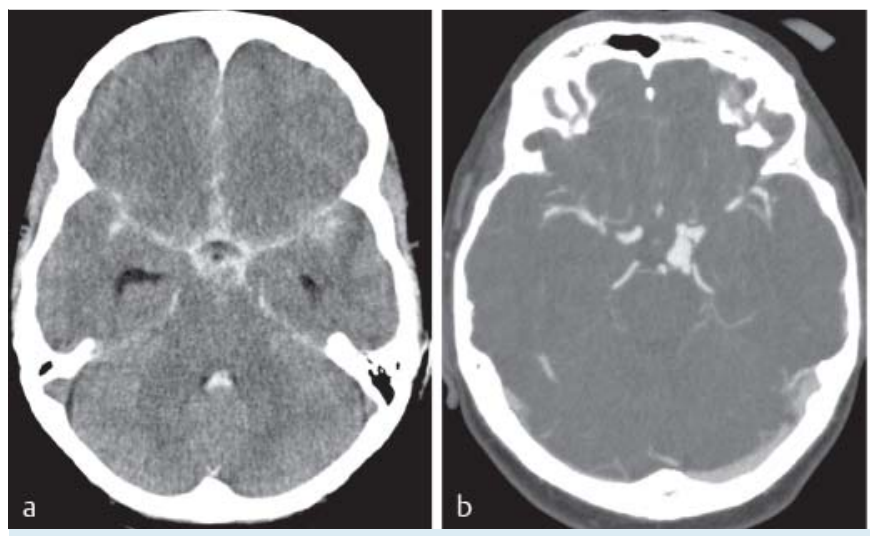

Fig. 1 a 28-year-old female patient with thunderclap headache with maximum pain within a few minutes; plain CCT with identification of extensive subarachnoid hemorrhage (SAH) in the basal cisterns. b Axial $10 \mathrm{~mm}$ MIPreconstruction of the same patient revealed a saccular aneurysm of the posterior communicating artery as the underlying cause of the hemor-
The primary differential diagnosis is isolated angiitis of the CNS, which likewise includes multiple stenosis of the intracranial vessels. However they are distally and eccentrically localized in the arterial lumen, and after contrast is administered, enhancement of the arterial wall can be observed. In addition, transient ischemia and/or hemorrhages can frequently be detected [24]. Typically, patients with RVCS show reversibility of the vascular changes within four weeks.

\section{Pituitary Apoplexy \\ Etiology}

Pituitary apoplexy is a rare but potentially life-threatening disorder which can be caused by ischemic or hemorrhagic necrosis. Very frequently, affected patients have a macroadenoma undergoing drug therapy or are taking oral anticoagulants; however, in the majority of cases, no cause can be ascertained [25].

\section{Symptomology}

This involves a sudden headache accompanied by progressive vision loss [25].

\section{Imaging}

Neuroimaging should be promptly performed on patients when pituitary apoplexy is suspected ( Table 3). MRI is the procedure of choice, whereby the pituitary signal is dependent upon the time point of the examination after the event. Differentiation from optic chiasma is best based upon T2w images. Contrast-enhanced images should be obtained in order to differentiate non-infarcted tissue. However, evidence of hemorrhage can also be obtained via CT (॰ Fig. 2).

\section{Dissection}

\section{Etiology}

In a dissection there is a tear in the arterial wall and subsequent subintimal hemorrhage. The result can be consecutive narrowing of the true lumen or formation of a pseudoaneurysm if the tear is subadventitial $[26,27]$. In the
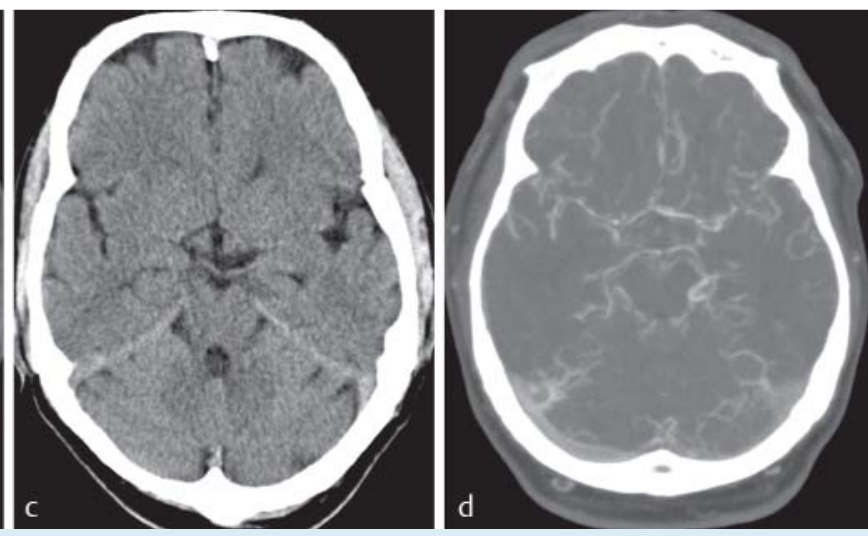

rhage. c 56-year old patient with thunderclap headache two days before admission and now dull headache. Plain cranial CT without evidence of SAH. d CT angiography of the same patient demonstrates extensive vasospasm of the intracranial vessels. CSF analysis was without evidence of SAH supporting the diagnosis of reversible cerebral vasoconstriction syndrome. 
majority of cases, dissection is spontaneous; additional risk factors include trauma or manipulation of the cervical spine and pre-existing connective tissue disease [26].

\section{Symptomology}

Headaches are the most common symptom of patients with dissection and as a rule they appear prior to focal-neurological symptoms [26]. They occur more frequently during dissection of the internal carotid artery compared to lesion of the vertebral artery ( $\bullet$ Fig. 3) Although headache generally exhibits gradual increase, up to $20 \%$ of affected patients present with $\mathrm{TCH}$. Typically pain is unilateral on the same side as the affected vessel and radiates from the neck into the head. In dissection of the vertebral artery, pain is prima- rily localized occipitally; in carotid dissection, pain radiates into the jaw, to the temple as well as around the eyes [26].

\section{Imaging}

MRI is the preferred imaging modality ( $\bullet$ Table 3 ). Non-enhanced T1-weighted images with fat saturation should be used to detect mural hematoma as confirmation of dissection, since after the second or third day, the mural hematoma appears hyperintense compared to the perfused lumen due to methemoglobin formation $[26,27]$. In the acute phase, mural hematoma appears isointense. Vessel imaging can be performed using either TOF MRA or CE MRA; the latter is preferred to display craniocervical vessels $[26,27]$. As
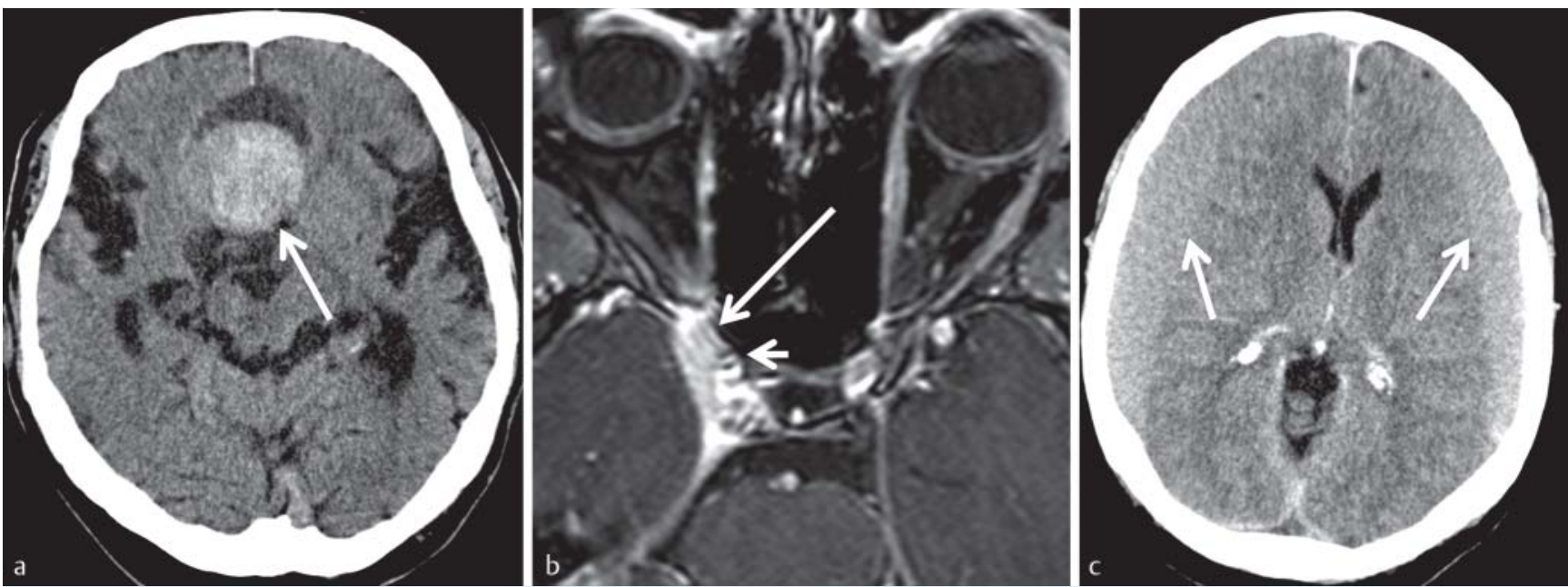

Fig. 2 Rare causes of secondary headache. a Plain axial cranial CT; 64-year old patient with known pituitary macroadenoma; TCH and sudden loss of vision. The intra- and suprasellar adenoma (arrow) is hyperdense indicating hemorrhagic pituitary apoplexy. b Contrast-enhanced axial T1-weighted sequence with fat suppression; 48-year-old female patient with right sided orbital pain and paralysis of the third and fourth cranial nerve. Strongly enhancing granulomatous tissue within the right cavernous sinus, superior orbital fissure and dura of the middle cranial fossa (long arrow) and concomitant narrowing of the right internal carotid artery (short arrow) as diagnostic landmark of Tolosa-Hunt-Syndrome. c Plain axial cranial CT three weeks after a mild traumatic brain injury; 74-year-old patient with oral anticoagulation treatment and two weeks history of headache. Subacute subdural hematoma above both hemispheres; the cortical surface (arrow) is displaced from the inner aspect of the cranium.
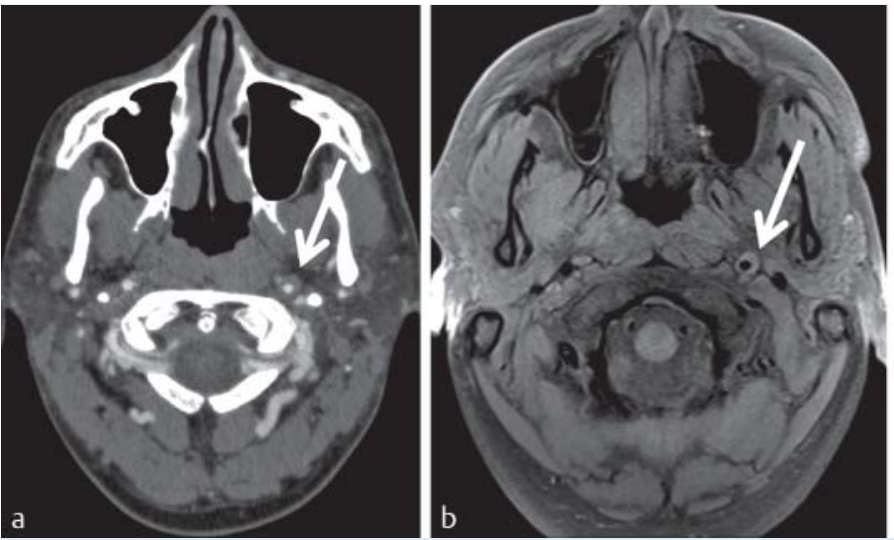

Fig. 3 a 27-year-old female patient with numb pain in the neck radiating into the temporal region after physical exercises. CT angiography demonstrates circular mural hematoma of the internal carotid artery (ICA). b Plain axial T1-weighted image with fat saturation of the same patient demonstrating the hyperintense mural hematoma of the ICA (arrow). The hematoma can be very nicely separated from the hypointense flow void causing
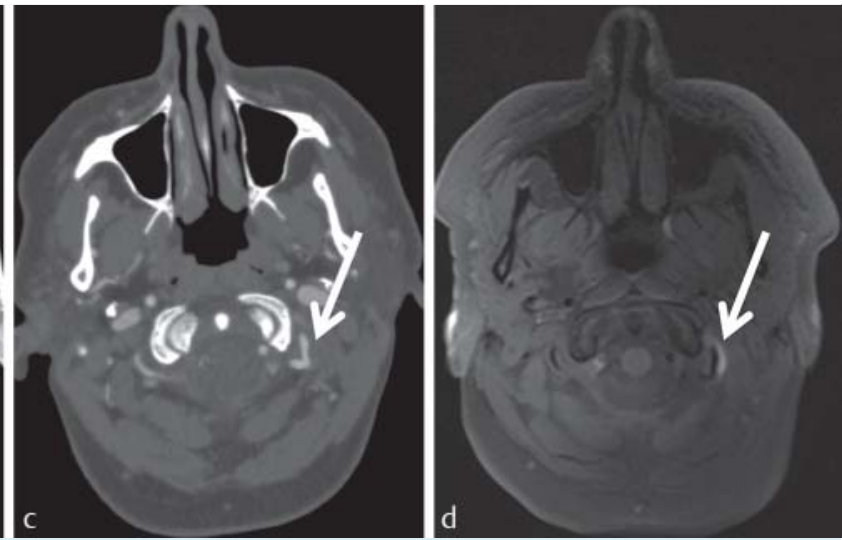

discrete narrowing of the lumen. c 37-year-old female patient with new onset of headache after playing with her toddler. CT angiography demonstrates discrete luminal irregularities of the dominant left vertebral artery within the horizontal part of atlas loop. $\mathbf{d}$ Plain axial T1-weighted image with fat saturation of the same patient demonstrates the hyperintense mural hematoma indicating arterial dissection. 
a rule, the arterial lumen tapers conically in a vascular occlusion caused by dissection (so-called "string sign").

Alternatively, CT angiography can be performed ( $\bullet$ Fig. 3). In this case, the intramural hematoma appears as localized wall thickening with accompanying variations in diameter. In clinical practice, Doppler ultrasound is successfully used as a screening examination and for follow-up. However, ultrasound findings frequently require follow-up diagnostic imaging, since only hemodynamic findings can be obtained and the etiology of the flow obstruction observed via Doppler sonography remains unclear [27].

\section{Cerebral Venous Sinus Thrombosis Etiology}

A number of risk factors exist for the formation of cerebral venous or sinus thrombosis [28]. In particular, pregnant women and those in the postpartum phase have an increased risk [29]. No causal factor can be identified in 20 $25 \%$ of cases.

\section{Symptomology}

The clinical symptom pattern is variable and can range from non-specific complaints to focal-neurological deficits through to coma. The guiding symptom, however, is headache [30]. Classically, headache has subacute onset and increases during gradual progression.

\section{Imaging}

Whereas in non-enhanced CCT, hyperdense interior veins have a high positive predictive value as an indirect reference point for thrombosis [31], the value of the already hyperdense sinus in non-enhanced CCT is debatable ( $\bullet$ Fig. 4); this is also true of the lack of flow-related signal loss (so-called flow void phenomenon) in T2-weighted images. In MRI, thrombus in the gradient echo appears as tubular signal cancellation due to blood degradation products. Further, susceptibility-weighted sequences, e.g. SWI (susceptibilityweighted imaging) or SWAN (susceptibility-weighted angiography) should be suitable to definitively identify thrombosis of cortical veins [32]. Nevertheless, vascular diagnosis should always follow in cases of doubt. In addition to CT angiography, this can also be in the form of MR angiography; however, contrast-enhanced MR venography ( $\bullet$ Table 3 ) is preferable to other techniques [32]. In both examination modalities, thrombus appears as a contrast defect ( $\bullet$ Fig. 4 ).

\section{Intracranial Cysts \\ Colloid cysts \\ Etiology}

Colloid cysts are protein-rich cysts on the roof of the third ventricle ( $\bullet$ Fig. 5 ) emanating from the endoderm [33].

\section{Symptomology}

Colloid cysts can be an incidental finding in cranial imaging or can manifest themselves via headache. The cause can be assumed to be intermittent blockage of the interventricular foramen. Since colloid cysts can exhibit rapid growth progression, they can result in the formation of life-threatening obstructive hydrocephalus [33]. Therefore neurosurgical therapy should be suggested to patients with colloid cysts.

\section{Imaging}

In more than $90 \%$ of cases, colloid cysts are found in the direct vicinity of the interventricular foramen [33] and in non-enhanced CCT appear as hyperdense round lesions (๑ Table 3). Cyst signal can be variable in an MRI, and depends on the viscosity and protein makeup of the cyst contents[34]. As a rule they appear hypointense in T2w and hyperintense in $\mathrm{T} 1 \mathrm{w}$. Since they can also appear to be CSF-isointense in an MRI, these cysts are frequently better distinguished using CCT.

\section{Pineal Cysts \\ Etiology \\ Pineal cysts are non-neoplastic cysts in the pineal canal.}

\section{Symptomology}

Generally these are asymptomatic findings ( $\bullet$ Fig. 5) during imaging of the neurocranium, found in $2.5-10 \%$ of all patients [33]. Because of this, some authors consider them only as a diagnosis of exclusion as a cause of headache [35]. In addition to a disturbance of melanin metabolism, another possible cause under discussion is intermittent compression of the tectal plate and aqueduct caused by very large cysts. Infrequently very large cysts can result in com-
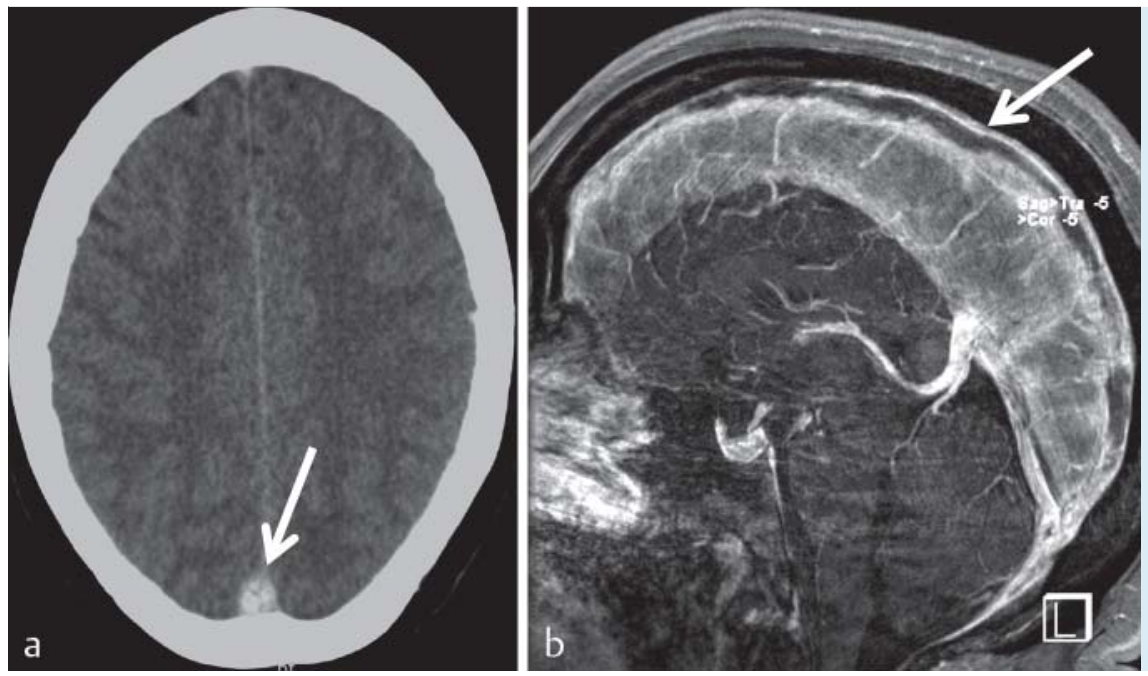

Fig. 4 a 27-year-old female patient 2 weeks postpartum. Slowly progressive headache which is not responding to therapy. Plain cranial CT demonstrates hyperdense superior sagittal sinus (arrow). b Sagittal MIP reconstruction (3 $\mathrm{mm}$ slice thickness) of a contrast-enhanced MR venography of the same patient demonstrating extensive thrombosis of the superior sagittal sinus (arrow). 

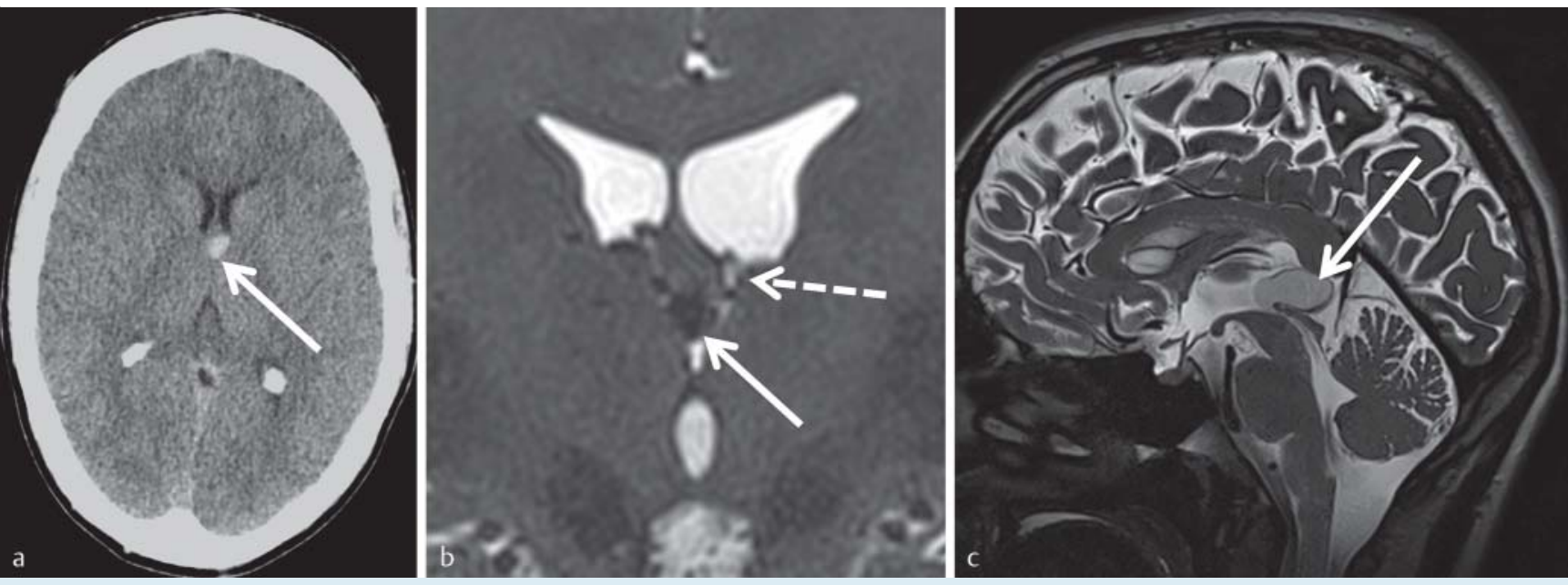

Fig. 5 a 23-year old patient with intermittent holocephalic headache. The colloid cyst in typical location at the roof of the third ventricle (arrow) appears hyperdense on plain cranial CT. b Coronal T2-weighted CISS sequence demonstrates the close anatomical relationship of the colloid cyst (arrow) to both foramen of Monro (dotted arrow). The cyst appears hypointense due the protein-rich content. c 25-year-old female fMRI volunteer subject with intermittent morning headache. Sagittal T2-weighted CISS image demonstrates a large pineal gland cyst extending just in front of the aqueduct. pression of the tectal plate accompanied by development of Parinaud's Syndrome.

Since the majority of cysts are asymptomatic and consistent in size or can even exhibit size reduction, follow-up is recommended; neurosurgical therapy is recommended only for cysts $>10-14 \mathrm{~mm}[31]$.

\section{Imaging}

Imaging can employ either CT or MRI ( $\bullet$ Table 3); MRI should always be used for follow-up. In CT, the cyst is hypodense; in T1w and T2w images it likewise indicates a hypointense signal. Cyst contents in FLAIR images appear hyperintense. Sagittal high-resolution T2w sequences (e.g. using CISS) should be acquired to accurately determine positional relationship of the cyst to the tectum and aqueduct (๑ Fig. 5).

Administration of contrast agent is not required for diagnosis. In up to $40 \%$ of cases, in both CT and MRI a linear marginal enrichment can be detected [33].

\section{Intracranial infections}

Etiology

In cases of cerebral infection, a distinction can be made between inflammation of the cerebral parenchyma (encephalitis) and cerebral membranes (meningitis). In the majority of cases, infections are either viral or bacterial in nature [36], and the path of infection is either hematogenic (e.g. during sepsis), through neighboring tissue (as a result of otitis media or sinusitis), directly or iatrogenically.

\section{Symptomology}

The guiding symptom of intracranial infection is headache and fever. Depending on the site and extent of the infection, additional neurological symptoms - including death - may occur.

Particular attention, however, should be paid to immune system-compromised and HIV-positive patients [37]. Intracranial pathology is found in cases of new-onset headache in up to $82 \%$ of these patients $[38,39]$ ( $\bullet$ Fig. 6 ). Therefore, cer- ebral imaging should be performed after new-onset headache, or if existing symptoms change in type or intensity.

\section{Imaging}

Meningitis is a clinical diagnosis supported by testing cerebrospinal fluid. The use of imaging, therefore, is to exclude contraindications for a lumbar puncture [40]. Performing non-enhanced CCT is sufficient here. In rare cases, moreover, complications or entry points for an inflammatory process can be identified ( $\bullet$ Fig. 6 ).

If encephalitis is suspected, an MRI should be performed ( $\bullet$ Table 3). Inflammatory changes appear as hyperintense signal alterations in FLAIR images, and in diffusion-weighted images can be distinguished earlier as hyperintense signal alteration. Administration of contrast agent is required, and contrast-enhanced images should be acquired on at least two planes.

\section{Cerebral Pseudotumors \\ Etiology}

CSF circulatory dysfunction can likewise be a source of headache. A particular form of this is the cerebral pseudotumor, also characterized as idiopathic intracranial hypertension [41]. This is understood to be an increase in intracranial pressure without evidence of an intracranial mass, hydrocephalus or edema.

\section{Symptomology}

Typical symptoms are headache and loss of visual acuity. Additional common symptoms include tinnitus as well as cranial nerve paresis; an ophthalmological examination may reveal papilledema. Typically young, overweight women and older slender men are affected, whereas among women, headache is in the forefront, and vision loss predominates among men [41].

\section{Imaging}

MRI is the examination modality of choice. Typical imaging findings are flattening of the papilla in axial T2w images as 

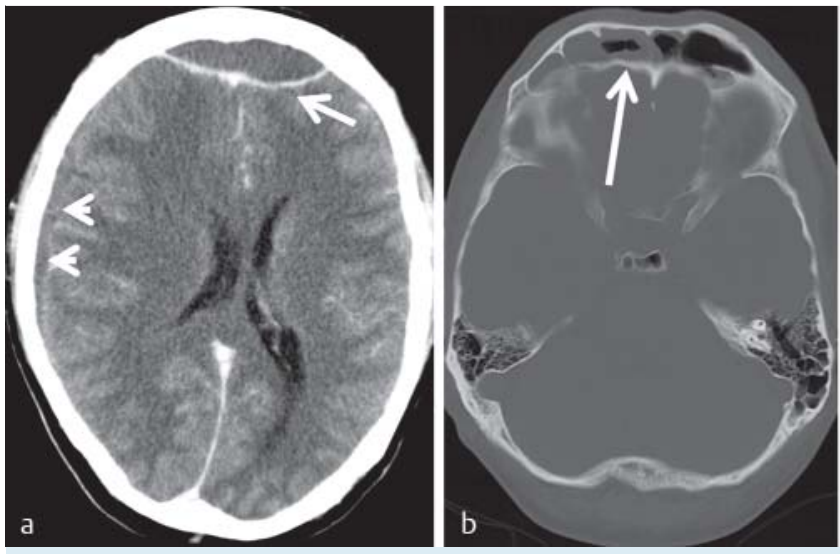

Fig. 6 a 43-year-old patient with new onset of headache and fever. CSF analysis demonstrated bacterial meningitis. Neurological worsening two days after onset of symptoms. Contrast-enhanced CT demonstrates frontal epidural abscess (arrow) and subdural empyema (arrow heads). b 29-yearold female patient with bacterial meningitis. Plain cranial CT in bone window level setting demonstrates extensive frontal sinusitis as possible un-
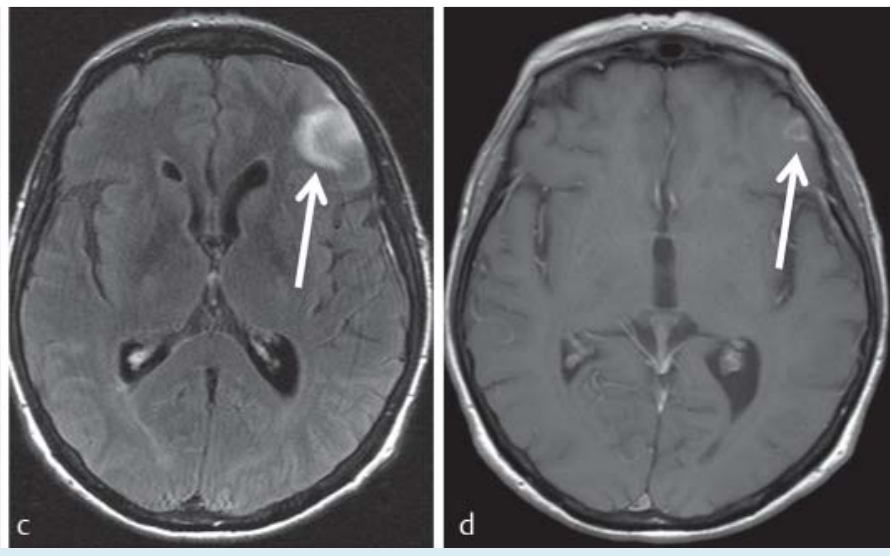

derlying cause. c 37-year-old HIV-positive patient (T4 cell count < 200/ $\mathrm{Ml}$ ) with new onset of headache. Axial T2-weighted FLAIR image demonstrates left frontal cortical and subcortical lesion. $\mathbf{d}$ Contrast-enhanced T1-weighted image of same patient demonstrates linear cortical enhancement. Histologically- proven cerebral toxoplasmosis.
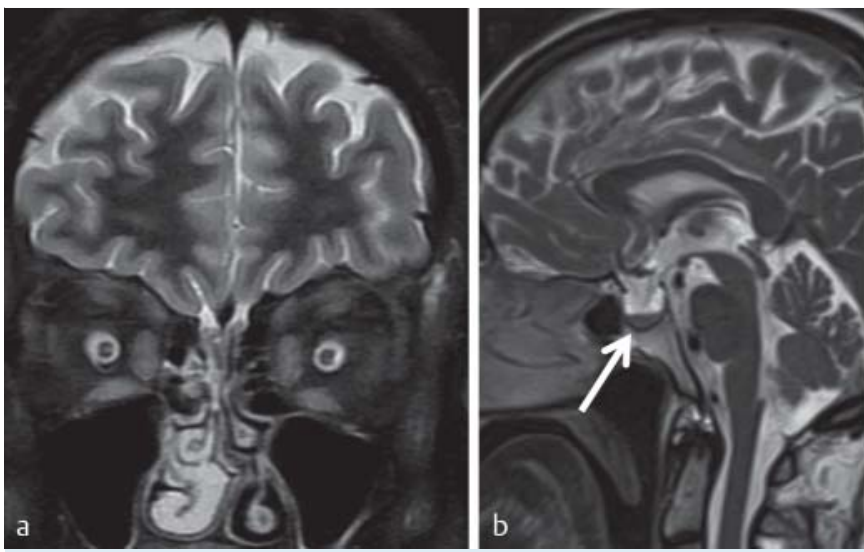

Fig. 7 a 32-year-old obese female patient (BMI $32 \mathrm{~kg} / \mathrm{m} 2$ ) with headache and progressive loss of vision. Coronal T2-weighted sequence demonstrates dilated optical nerve sheaths on both sides (arrow) as indirect sign of pseudotumor cerebri. b Sagittal T2-weighted image of the same patient
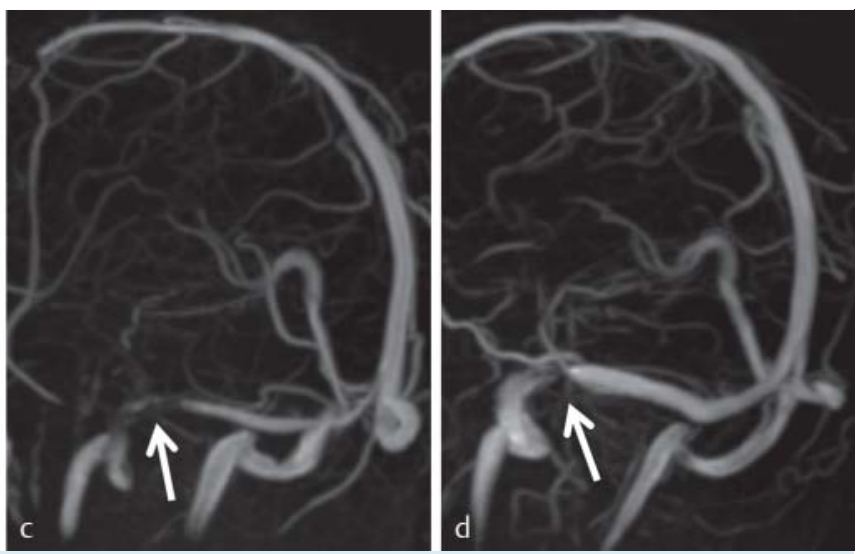

demonstrates "empty sella"-phenomenon. c Venous TOF angiography of the same patient delineating stenosis of the lateral transverse sinus (arrow). d The stenosis of the transverse sinus is reversible (arrow) after spinal tap test highly suggestive for the diagnosis pseudotumor cerebri. well as a gyrose optic nerve. Coronal images reveal an enhancement of the optic nerve sheath; this phenomenon can be easily assessed using T2w images with fat saturation ( $\odot$ Table 3). Additionally, the pituitary is flattened (so-called empty sella syndrome). Venous angiography frequently reveals stenosis in the transverse sinus [42]. Due to shorter examination time and reduced susceptibility to artifacts, contrast-enhanced MR venography is preferable to TOF venography ( $\bullet$ Table 2 ). Morphological changes in the image can be reversed after lumbar puncture, a diagnostic indicator (० Fig. 7)

\section{CSF Leak Syndrome}

\section{Etiology}

In contrast, the CSF leak syndrome is a relatively recent diagnosis that is underdetected. The pathophysiological basis is that the loss of CSF results in caudal displacement of the brain with subsequent strain on the richly innervated dura, causing headache [43]. As it progresses, pain symptoms become chronic. A distinction can be made between a primary idiopathic form and a secondary form. Causes of the secondary form can be meningeal diverticula generally occurring along the nerve root, or dural defects. The latter can be iatrogenic or caused by degenerative osteophytes. As many as $2 / 3$ of patients additionally exhibit connective tissue disease.

\section{Symptomology}

The disease pattern is marked by orthostatic headache normally occurring after 15 minutes in the standing position and improving in the reclining position. Women are more frequently affected than men, and peak age is about 40 [43]

\section{Imaging}

Diagnosis must be performed using MRI ( $\bullet$ Table 3 ) [43]. Intracranial subdural hygromas and sinus dilation are typically found, and after administration of contrast agent, the meninges exhibit significant contrast accumulation ( $\boldsymbol{0}$ Fig. 8). Spinal epidural fluid deposits can be detected. These are easily detected in sagittal T2-weighted images with fat satura- 

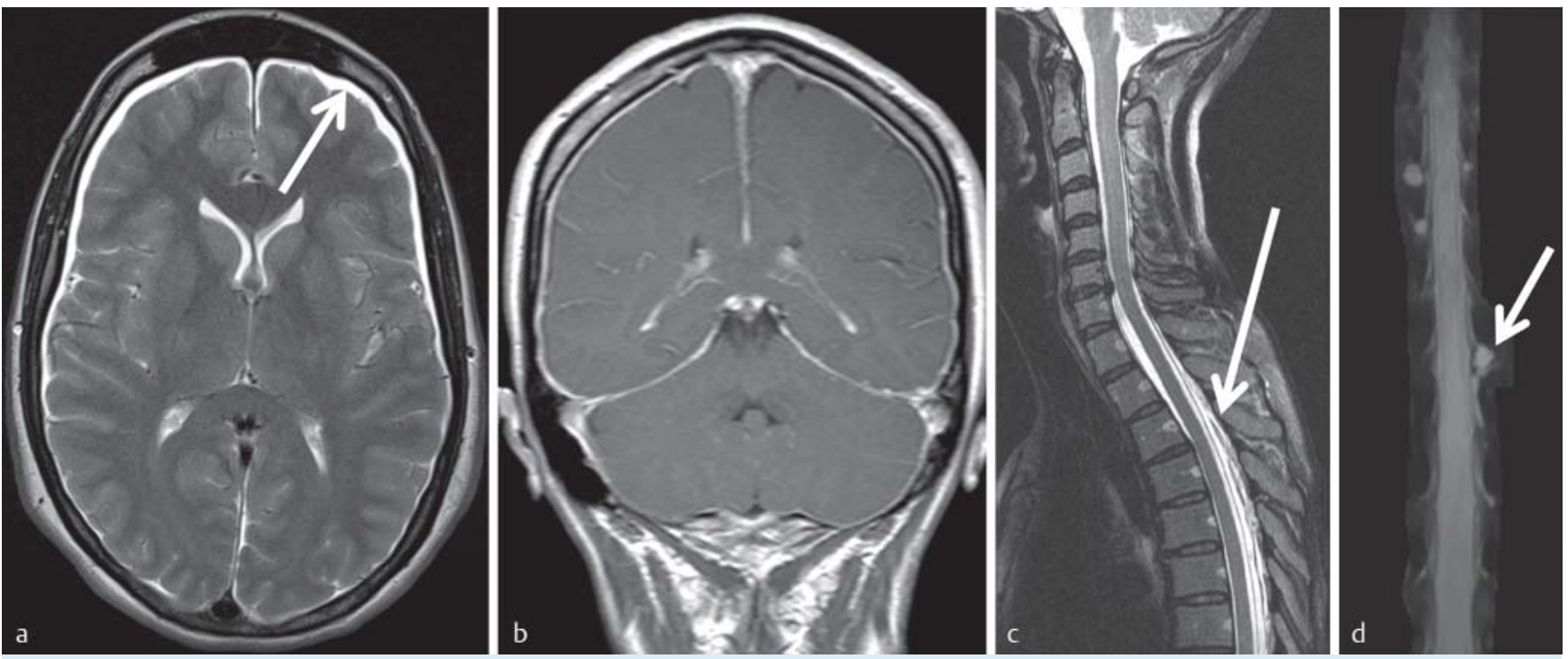

Fig.8 a 43-year-old female dancer with progressive headache in upright position. Axial T2-weighted image demonstrates bilateral frontal hygroma (arrow). b Contrast enhanced coronal T1-weighted image of the same patient demonstrating thickened and strongly enhanced meninges and tentorium. c Sagittal T2-weighted image with fat suppression of the spine de- monstrates epidural effusion (arrow) as indirect spinal sign of intracranial hypotension. d Coronal T2-weighted MR-myelogram delineates multiple spinal nerve root diverticula as possible cause of the CSF leakage. Complaints resolved after epidural blood patch at the level of the largest diverticulum. tion, since in these sequences, a distinction can be reliably made between epidural fluid and fat. Coronal T2-weighted images are suitable to identify nerve root sleeve cysts as a possible cause of CSF loss ( $\mathbf{F i g . 8}$ ) In up to $20 \%$ of cases, the MRI is unremarkable, however. In addition to diagnosis, radiology also offers the possibility of interventional radiological therapy using an epidural blood patch [44].

\section{Sinusitis}

\section{Etiology}

There are a number of triggering factors for sinusitis. With respect to their temporal progression, a distinction can be made between an acute (less than 8 weeks duration or fewer than 4 episodes per year) and a chronic form (more than 8 weeks duration or more than 4 episodes per year) [45].

\section{Symptomology}

Sinus headaches as a rule generally have a dull character and mainly occur with involvement of the sphenoid sinus (० Fig.9).

\section{Imaging}

Acute sinusitis is generally a clinical diagnosis and does not require imaging. However, imaging should be performed in cases of chronic sinusitis to assess the anatomy with respect to surgical therapy [46], in cases of immune system-deficient patients, new onset focal neurological deficit, or if complications are suspected [45, 47].

Due to their limited sensitivity and specificity, conventional $\mathrm{X}$-ray images are obsolete for the diagnosis of sinusitis; instead a low-dose CT should be performed [47]. Sinusitis is accompanied by swelling of the mucosa, which appears in CT as iso- to hypodense; in MRI it appears hyperintense in $\mathrm{T} 2 \mathrm{w}$ images, and isointense to the musculature in T1 w images. Chronic cases may result in sclerosis of the sinus walls which is easily detectable in CT, and which can reduce the volume of the affected sinus.

If there is suspicion of intracranial or orbital complications ( $\bullet$ Fig.9), MRI is superior to CT as a diagnostic modality. These can be well-differentiated in coronal T2-weighted images with fat saturation, as well as in fat-saturated T1weighted images after administration of contrast agent [47].

\section{Trigeminal Neuralgia \\ Etiology}

Trigeminal neuralgia (TN) is a neurovascular compression syndrome; according to the IHS classification of headache, it belongs to the group of "cranial neuralgias, central and primary facial pain and other headaches." The cause is considered to be compression of the nerve in its root entry zone by an artery [48], generally the superior cerebellar artery or the anterior inferior cerebellar artery ( $\bullet$ Fig. 10).

\section{Symptomology}

Typically patients complain of intense pain lasting but a few seconds in the region of the second or third trigeminal branch; in only $5 \%$ of cases is the pain in the territory of the ophthalmic nerve (first branch). Pain can occur spontaneously or can be provoked by contact with trigger points [48].

\section{Imaging}

If TN is suspected, diagnosis should be performed using MRI ( $\bullet$ Table 3). The success of surgical therapy correlates with the preoperative verification of neurovascular compression. The examination protocol to substantiate this should include axial high-resolution T2-weighted images (e.g. CISS sequence) in addition to arterial TOF angiography. It should be noted, however, that among healthy subjects, vesselnerve contact can likewise be observed; therefore there 

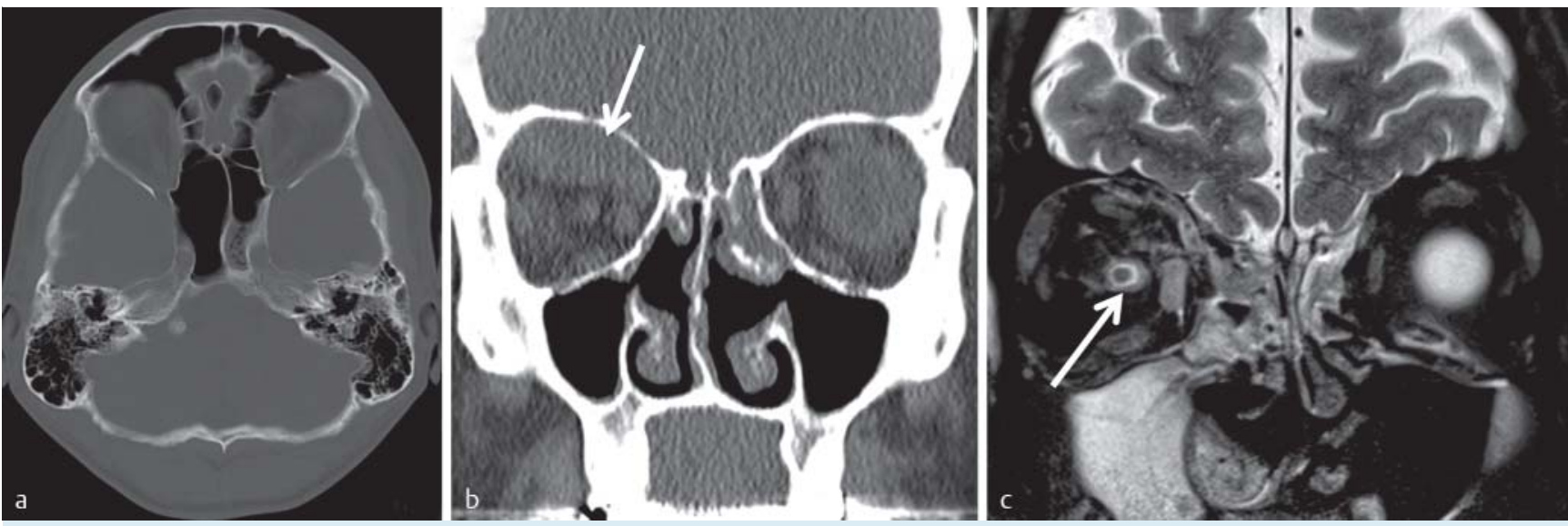

Fig. 9 a 33-year-old patient with new onset of holocephalic headache. Plain cranial CT in bone window level setting demonstrating opacification of the left sphenoid sinus indicating acute sinusitis. $\mathbf{b} 43$-yearold patient with chronic sinusitis and recent exacerbation. Two-day history of pain in the right eye and diplopia. Coronal CT reconstruction demonstrates a subper- iostal abscess at the roof of the orbit. c 47-year-old female patient with chronic sinusitis. Acute exacerbation with new onset of headache and pain in the right eye. Coronal T2-weighted images demonstrate subtle inflammatory changes around the optic nerve and extra- and intraconal fat tissue. must always be a correlation between image findings and clinical symptoms [48]. A differential diagnosis of multiple sclerosis should be considered, particularly in cases of young women with new-onset TN or new-onset atypical facial pain ( $\bullet$ Fig. 10).

\section{Tolosa-Hunt Syndrome Etiology}

Together with trigeminal neuralgia, Tolosa-Hunt syndrome (THS) is counted among the group of cranial neuralgias. The disorder is characterized by inflammatory granulomatous changes of unknown etiology in the cavernous sinus and superior orbital fissure which can extend into the orbit and continue intracranially [49].

\section{Symptomology}

THS is an episodically recurring pain in the orbit, accompanied by paresis of the oculomotor nerve and trochlear nerve and/or the abducens nerve [49].

\section{Imaging}

MRI is the modality of choice. In addition to prompt improvement of symptoms within 72 hours after administration of cortisone, detection of inflammatory changes ( Fig. 2) is one of the essential diagnostic criteria [49]. To demonstrate granulomatous changes, contrast-enhanced images with fat saturation should be acquired using axial and coronal layer orientation (๑ Table 3 ).

\section{Post-traumatic Headache \\ Etiology}

Headache is one of the most common symptoms after traumatic brain injury (TBI), and the most frequent form of secondary headache $[4,50]$. The exact pathophysiological mechanism is not understood in the majority of cases. Paradoxically, mild TBI is more frequently associated with chronic post-traumatic headache than severe TBI [50].

\section{Symptomology}

According to guidelines, post-traumatic headache appears within seven days after the trauma and is considered acute if it lasts less than 3 months [4]. Post-traumatic headache does not exhibit specific characteristics, and current studies have shown that in the majority of cases, post-traumatic headaches have a migrainoid character [50]. In addition they can be associated with impairment of cognitive function, leading to a significant reduction in the quality of life.

\section{Imaging}

In rare cases there is a correlation in morphological imaging [50]; therefore, initial imaging can use non-enhanced CCT. In the differential diagnosis, a subdural hematoma should be considered, particular in older patients undergoing anticoagulant therapy ( $\bullet$ Fig. 2). CCT is the imaging modality of choice. Hematoma appears hyperdense compared to the adjoining cerebral parenchyma. However, with progression it reduces in density, so that the hematoma can appear isodense or hypodense with respect to the brain. Therefore it is important to note whether the cortical relief touches the calvaria, which is otherwise an indication of subdural hematoma.

\section{Summary}

The majority of patients with headaches suffer from primary headache for which imaging only rarely yields indicatory findings.

In contrast there are a number of less common secondary headaches that are an expression of an underlying disorder requiring additional clarification.

Even in cases in which insufficient evidence-based data is available, at the least a non-enhanced CCT to exclude intracranial pathology should be performed on patients above 50 years of age with new-onset or altered headache. Further, imaging is indicated if previously identified headache changes in character, if accompanying focal-neurological deficit or systemic secondary reactions are present, as well 

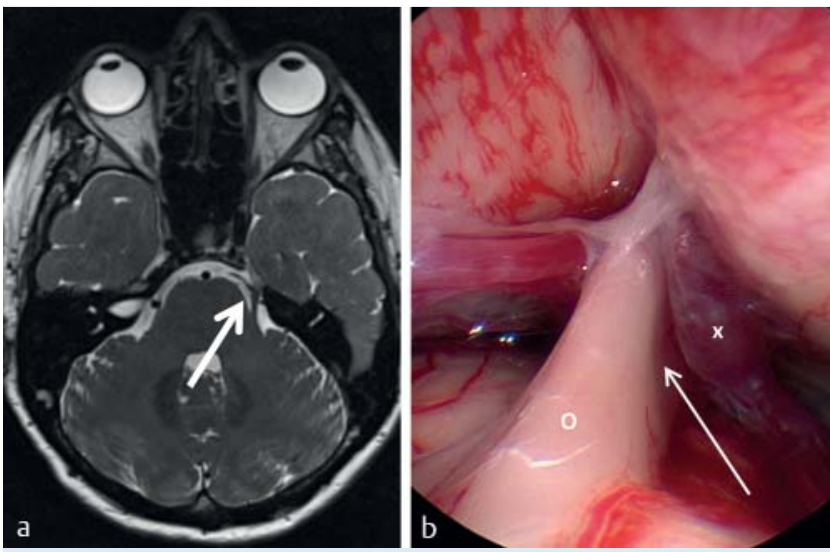

Fig. 10 a 57-year-old female patient with 7-month history of recurrent pain in the territory of the second trigeminal branch. Axial T2-weighted CISS image demonstrates neurovascular compression of the root entry zone of the left trigeminal nerve by a loop of the left superior cerebellar artery. $\mathbf{b}$ Intraoperative photography of the same patient. The nerve (o) is flattened (arrow) by the pulsatile compression of the vascular loop ( $\mathrm{x}$ ).
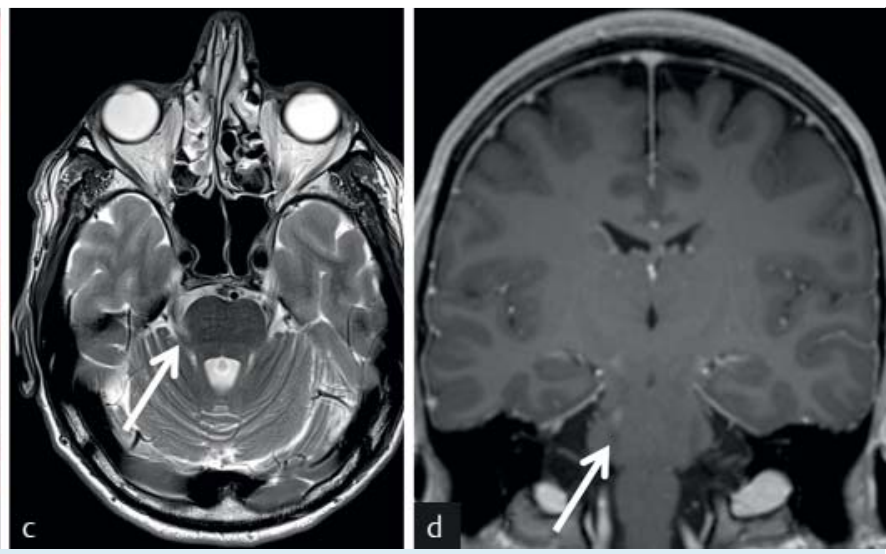

c 24-year-old female patient with 2-week history pain in the territory of the first trigeminal branch. Axial T2-weighted image demonstrates demyelinating lesion at the root exit zone. $\mathbf{d}$ Coronal reconstructed contrast-enhanced T1-weighted MPR image demonstrates enhancement of the lesion indicating active inflammation. as in cases of immune system-compromised patients with new-onset headache. Selection of the imaging modality is based on the suspected underlying disorder and the general clinical situation of the patient.

\section{References}

1 Rasmussen BK, Jensen R, Schroll $M$ et al. Epidemiology of headache in a general population - a prevalence study. Journal of clinical epidemiology $1991 ; 44: 1147-1157$

2 Kohlmann T. Musculoskeletal pain in the population. Schmerz (Berlin, Germany) 2003; 17: 405-411

3 Jordan JE. Headache. American journal of neuroradiology 2007; 28: $1824-1826$

4 (IHS) HCCotIHS. The International Classification of Headache Disorders, 3rd edition (beta version). Cephalalgia: an international journal of headache 2013; 33: 629-808

5 Dodick DW. Clinical practice. Chronic daily headache. The New England journal of medicine 2006; 354: 158-165

6 Tsushima Y, Endo K. MR imaging in the evaluation of chronic or recurrent headache. Radiology 2005; 235: 575-579

7 Stuckey SL, Goh TD, Heffernan T et al. Hyperintensity in the subarachnoid space on FLAIR MRI. American journal of roentgenology 2007; 189: $913-921$

8 Ozsarlak O, Van Goethem JW, Maes M et al. MR angiography of the intracranial vessels: technical aspects and clinical applications. Neuroradiology 2004; 46: 955-972

9 Kruit MC, van Buchem MA, Launer LJ et al. Migraine is associated with an increased risk of deep white matter lesions, subclinical posterior circulation infarcts and brain iron accumulation: the population-based MRI CAMERA study. Cephalalgia: an international journal of headache 2010; 30: 129-136

10 Swartz RH, Kern RZ. Migraine is associated with magnetic resonance imaging white matter abnormalities: a meta-analysis. Archives of neurology 2004; 61: 1366-1368

11 Palm-Meinders IH, Koppen H, Terwindt GM et al. Structural brain changes in migraine. JAMA: the journal of the American Medical Association 2012; 308: 1889-1897

12 Bashir A, Lipton RB, Ashina $S$ et al. Migraine and structural changes in the brain: a systematic review and meta-analysis. Neurology 2013; 81: $1260-1268$

13 May A. New insights into headache: an update on functional and structural imaging findings. Nature reviews Neurology 2009; 5: 199-209

14 Schwedt TJ. Thunderclap headaches: a focus on etiology and diagnostic evaluation. Headache 2013; 53: 563-569

15 van Gijn J, Kerr RS, Rinkel GJ. Subarachnoid haemorrhage. Lancet 2007; 369: $306-318$
16 Marder CP, Narla V, Fink JR et al. Subarachnoid hemorrhage: beyond aneurysms. American journal of roentgenology 2014; 202: 25-37

17 McCormack RF. Third-generation CT has $100 \%$ sensitivity and specificity for identifying subarachnoid haemorrhage when it is carried out within $6 \mathrm{~h}$ of headache onset. Evidence-based medicine 2012; 17: $27-28$

18 Verma RK, Kottke R, Andereggen L et al. Detecting subarachnoid hemorrhage: comparison of combined FLAIR/SWI versus CT. European journal of radiology 2013; 82: 1539-1545

19 Deutsche Gesellschaft für Neurologie. Leitlinie Diagnostik und apparative Zusatzuntersuchungen bei Kopfschmerzen. http://www.awmf. org/leitlinien/detail/11/030-110.html

20 Ducros A. Reversible cerebral vasoconstriction syndrome. Lancet neurology 2012; 11: $906-917$

21 Yancy H, Lee-Iannotti JK, Schwedt TJ et al. Reversible cerebral vasoconstriction syndrome. Headache 2013; 53: 570-576

22 Marder CP, Donohue MM, Weinstein JR et al. Multimodal imaging of reversible cerebral vasoconstriction syndrome: a series of 6 cases. American journal of neuroradiology 2012; 33: 1403-1410

23 Chen SP, Fuh JL, Wang SJ et al. Magnetic resonance angiography in reversible cerebral vasoconstriction syndromes. Annals of neurology 2010; 67: 648-656

24 Abdel Razek AA, Alvarez H, Bagg S et al. Imaging spectrum of CNS vasculitis. Radiographics: a review publication of the Radiological Society of North America, Inc 2014; 34: 873-894

25 Bi WL, Dunn IF, Laws ER Jr. Pituitary apoplexy. Endocrine 2014, [epub ahead of print]

26 Rodallec $M H$, Marteau V, Gerber $S$ et al. Craniocervical arterial dissection: spectrum of imaging findings and differential diagnosis. Radiographics: a review publication of the Radiological Society of North America, Inc 2008; 28: 1711 - 1728

27 Hahnel S, Stippich C, Hartmann M et al. Injury of craniocervical arteries: imaging findings and therapy. Fortschr Röntgenstr 2007; 179: 119129

28 Masuhr F, Mehraein S, Einhaupl K. Cerebral venous and sinus thrombosis. Journal of neurology 2004; 251: 11-23

29 Edlow JA, Caplan LR, O'Brien $K$ et al. Diagnosis of acute neurological emergencies in pregnant and post-partum women. Lancet neurology 2013; $12: 175-185$

30 Weimar C. Diagnosis and treatment of cerebral venous and sinus thrombosis. Current neurology and neuroscience reports 2014; 14 : 417

31 Linn J, Pfefferkorn T, Ivanicova K et al. Noncontrast CT in deep cerebral venous thrombosis and sinus thrombosis: comparison of its diagnostic value for both entities. American journal of neuroradiology 2009; 30: $728-735$

32 Linn J, Bruckmann H. Cerebral Venous and Dural Sinus Thrombosis*: State-of-the-Art Imaging. Clinical neuroradiology 2010; 20: 25-37 
33 Osborn AG, Preece MT. Intracranial cysts: radiologic-pathologic correlation and imaging approach. Radiology 2006; 239: 650-664

34 El Khoury C, Brugieres P, Decq P et al. Colloid cysts of the third ventricle: are MR imaging patterns predictive of difficulty with percutaneous treatment? American journal of neuroradiology 2000; 21: 489-492

35 Molina-Martinez FJ, Jimenez-Martinez MC, Vives-Pastor B. Some questions provoked by a chronic headache (with mixed migraine and cluster headache features) in a woman with a pineal cyst. Answers from a literature review. Cephalalgia: an international journal of headache 2010; 30: $1031-1040$

36 Hahnel S, Storch-Hagenlocher B, Kress B et al. Infectious diseases of brain parenchyma in adults: imaging and differential diagnosis aspects. Fortschr Röntgenstr 2005; 177: 1349-1365

37 Krope K, Speil A, Pantazis G et al. MR imaging in the diagnosis of primary and secondary cerebral infections. Fortschr Röntgenstr 2013; 185: $539-545$

38 Edlow JA, Panagos PD, Godwin SA et al. Clinical policy: critical issues in the evaluation and management of adult patients presenting to the emergency department with acute headache. Annals of emergency medicine 2008; 52: 407-436

39 Joshi SG, Cho TA. Pathophysiological mechanisms of headache in patients with HIV. Headache 2014; 54: 946 -950

40 van Crevel H, Hijdra A, de Gans J. Lumbar puncture and the risk of herniation: when should we first perform CT? Journal of neurology 2002; 249: $129-137$

41 Degnan AJ, Levy LM. Pseudotumor cerebri: brief review of clinical syndrome and imaging findings. American journal of neuroradiology 2011; 32: 1986-1993
42 Rohr A, Riedel C, Reimann G et al. Pseudotumor cerebri: quantitative invivo measurements of markers of intracranial hypertension. Fortschr Röntgenstr 2008; 180: 884-890

43 Schievink WI, Maya MM, Louy C et al. Diagnostic criteria for spontaneous spinal CSF leaks and intracranial hypotension. American journal of neuroradiology 2008; 29: 853-856

44 Kranz PG, Gray L, Taylor JN. CT-guided epidural blood patching of directly observed or potential leak sites for the targeted treatment of spontaneous intracranial hypotension. American journal of neuroradiology 2011; 32: 832-838

45 Cornelius RS, Martin J, Wippold FJ et al. ACR appropriateness criteria sinonasal disease. Journal of the American College of Radiology: JACR 2013; 10: 241 - 246

46 Hoang JK, Eastwood JD, Tebbit CL et al. Multiplanar sinus CT: a systematic approach to imaging before functional endoscopic sinus surgery. American journal of roentgenology 2010; 194: W527-W536

47 Damann F, Bootz F, Cohnen $M$ et al. Diagnostic Imaging modalities in head and neck disease. Deutsches Arzteblatt international 2014; 111 : 417-423

48 Langner S, Schroeder HW, Hosten $N$ et al. Diagnosing neurovascular compression syndromes. Fortschr Röntgenstr 2012; 184: 220-228

49 Colnaghi S, Versino M, Marchioni E et al. ICHD-II diagnostic criteria for Tolosa-Hunt syndrome in idiopathic inflammatory syndromes of the orbit and/or the cavernous sinus. Cephalalgia: an international journal of headache 2008; $28: 577-584$

50 Russo A, D'Onofrio F, Conte F et al. Post-traumatic headaches: a clinical overview. Neurological sciences: official journal of the Italian Neurological Society and of the Italian Society of Clinical Neurophysiology 2014; 35 (Suppl 1): 153-156 